\title{
Differences between Road Bike and Mountain Bike on Decreasing of Blood Sugar Level after Cycling For 30 Minutes
}

\author{
$1^{\text {st }}$ Yasep Setiakarnawijaya \\ Faculty of Sport Science \\ Universitas Negeri Jakarta \\ Jakarta, Indonesia \\ yasep.s@unj.ac.id
}

\begin{abstract}
This study aims to determine the difference in blood sugar level decrease after cycling for 30 minutes using road bike and mountain bike. The concept of measurement of blood glucose level using glucometer and it is taken after the sample doing cycling for 30 minutes. This Quasi experimental research was conducted on 30 people of sample where each group consists of 15people. This research is done with purposive sampling technique. The results showed that the average decrease in blood sugar level after 30 minutes of cycling using mountain bike is $23.4 \mathrm{mg} / \mathrm{dl}$ while the road bike is 30.3 . Statistical analysis using independent sample t-test results show that there is a significant difference blood sugar level decreasing between cycling for 30 minutes using a road bike and mountain bike.
\end{abstract}

Keywords-blood sugar level, cycling, mtb, roadbike introduction

\section{INTRODUCTION}

Diabetes is a chronic disease that occurs either when the pancreas does not produce enough insulin or when the body cannot effectively use the insulin it produces. Insulin is a hormone that regulates blood sugar. Hyperglycaemia, or raised blood sugar, is a common effect of uncontrolled diabetes and over time leads to serious damage to many of the body's systems, especially the nerves and blood vessels.

Diabetes is recognised as the world's fastest growing chronic condition. The number of people with type 2 diabetes is growing in each country. In 2013, diabetes caused 1.5 million deaths globally. Higher blood glucose levels also caused an additional 2.2 million deaths, by increasing the risks of cardiovascular and other diseases. (WHO Fact Sheet of Diabetes, 2017)

Now a day many people aware of diabetes risk for their life. People try to get better life and doing some sport to reduce the risk of diabetes. Cycling is on of the most popular sport among urban citizen. There are many various of cycling activity but most of the are Road bike and Mountain Bike.

Road bike and Mountain Bike have many different characteristics that affect our health phisically and phisiologically. The main effect of cycling is can reduce the blood sugar level in our body. There must be different affect of cycling for 30 toward blood sugar level between road bike and mountain bike.

\section{MATERIALS AND METHODS}

This study aims to determine the difference in blood sugar level decrease after cycling for 30 minutes using road bike and mountain bike. Subject of this Research are male student 1618 years old, BMI between 20-23 and a reguler cyclist for each type of cycling.

The concept of measurement of blood glucose level using glucometer and it is taken after the sample doing cycling for 30 minutes. This quasi experimental research was conducted on 30 people of sample where each group consists of 15 peoples.

This research is done with purposive sampling technique. Data analysis conducted by Independent sample $t$ test to determine differences between Road bike and Mountain Bike in decreasing blood glucose level.

\section{RESULT AND DISCUSSION}

The results of this research showed in the table below.

TABLE 1. DESCRIPTION OF BLOOD GLUCOSE LEVEL BEFORE AND

\begin{tabular}{|rrr|rrr|}
\hline \multicolumn{5}{|c|}{ Road Bike } & \multicolumn{3}{c|}{ MTB } \\
Before & After & Delta & Before & After & Delta \\
\hline 113 & 88 & 25 & 106 & 90 & 16 \\
112 & 87 & 25 & 107 & 91 & 16 \\
116 & 91 & 25 & 105 & 89 & 16 \\
115 & 90 & 25 & 103 & 87 & 16 \\
117 & 92 & 25 & 104 & 88 & 16 \\
100 & 75 & 25 & 106 & 90 & 16 \\
105 & 80 & 25 & 107 & 91 & 16 \\
109 & 84 & 25 & 103 & 87 & 16 \\
109 & 84 & 25 & 101 & 85 & 16 \\
102 & 77 & 25 & 102 & 86 & 16 \\
110 & 85 & 25 & 103 & 87 & 16
\end{tabular}




\begin{tabular}{|rll|lll|}
99 & 74 & 25 & 105 & 89 & 16 \\
105 & 80 & 25 & 106 & 90 & 16 \\
112 & 87 & 25 & 107 & 91 & 16 \\
104 & 79 & 25 & 106 & 90 & 16 \\
\hline
\end{tabular}

TABLE 2. COMPARISON BETWEN ROADBIKE AND MTB

\begin{tabular}{|r|r|r|r|}
\hline \multicolumn{1}{|c|}{ Type } & Mean & \multicolumn{1}{c|}{ SD } & \multicolumn{1}{c|}{ SE } \\
\hline Roadbike & 30,3333 & 8,58293 & 2,2161 \\
\hline MTB & 23,4667 & 4,47001 & 1,15415 \\
\hline
\end{tabular}

The results showed that the average decrease in blood glucose level after 30 minutes of cycling using mountain bike is $23.4 \mathrm{mg} / \mathrm{dl}$ while the decrease in blood glucose levels using road bike for 30 minutes is $30.3 \mathrm{mg} / \mathrm{dl}$.

TABLE 3. T-TEST FOR EQUALITY OF MEANS

\begin{tabular}{|c|cccc|}
\hline t-test & t & df & p-value & $\begin{array}{c}\text { Mean } \\
\text { Difference }\end{array}$ \\
\hline Value & 2,748 & 21,074 & 0,012 & 6,86667 \\
\hline
\end{tabular}

T-test show that the p-value is lower than alpha (0.05) so there is a significant difference in the decrease in blood sugar level between cycling for 30 minutes using a road bike and mountain bike. Thus we can noted that Road bike give a better effect in decreasing blood glucose level than MTB.

Blood is a fluid that flows in the vascular system found in humans and animals [5]. Blood is a vehicle or medium for transportation of nutrients throughout the body. Function in the blood transports oxygen, nutrients and waste products of metabolism from the heart throughout the body and back again to the heart [10]

At this moment, nearly 10 percent of the population-are living with diabetes. The Center for Disease Control and Prevention projects that up to one in three Americans will have diabetes by 2050. Scientists are still trying to figure out what exactly is going on (diet and lifestyle certainly play large roles), but one thing is for certain: A lot of people are living with a fairly complex condition, and the situation will worsen. [WHO, 2017]

Bicycling at a speed between 12 and $14 \mathrm{mph}$ helps a 175pound person burn about 346 calories, according to HealthStatus. The same person burns about 420 calories in 30 minutes of pedaling at a pace of 14 to $16 \mathrm{mph}$. If you aren't interested in bicycling on the road, swap your road bike for a mountain bike. In 30 minutes of mountain biking, a 175pound person burns about 336 calories. At the gym, the same person burns about 451 calories pedaling a stationary bike at a vigorous pace. [6]

Riding bicycle is an effective way to improve overall health. As a low-impact sport, bicycling won't lead to joint pain as burn calories, build muscle and strengthen the body. This activity also improves cardiovascular health, mobility and bone strength, while helping reduce the stress. [6].

This research showed relevan result with E.H. Azhar .The results showed that cycling for 20 minutes affect changes in blood sugar levels significantly $(\mathrm{p}=0.000)$. The average reduction in blood sugar levels after the intervention is 25.0 $\mathrm{mg} / \mathrm{dl}$. Cycling for 20 minutes if done regularly can help keep blood sugar levels in the normal rate. [4]

But showed some irelevan result with Rohankar, et.al that stated that walking and yoga Exercise are more significant as compared to the swimming and cycling Exercise and lead to develop proper glucose control [9].

\section{CONCLUSION}

T-test results show that there is a significant difference in the decrease in blood glucose level between cycling for 30 minutes using a road bike and mountain bike, which is cycling for 30 minutes using road bike showing the bigger decrease of blood sugar level. It is statistically approved that road bike is more efficient to reduce blood glucose level than mtb.

\section{ACKNOWLEDGMENT}

In this papers I would like to acknowledge my students Muhammad Ilham Alamsyah dan Muhammad Mar'i for providing me the data

\section{REFERENCES}

[1] Astrand M.D, Text Book of Work Physiology (Student Edition: Sidney, 1970), h. 16.

[2] Brian J. Sharkey, Fitness and Health (Jakarta: P.T Raja Grafindo Persada, 2003), h. 68.

[3] Charles Fox dan Anne Kilvert, Befriended with type 2 diabetes (Jakarta: PT Niaga Swadaya, 2011), h. 49

[4] E H Azhar and A S Sutopo 2017, Effect of Cycling 20 Minutes of Blood Sugar Levels in Male Students of Senior High School 9 Tangerang 2015, IOP Conf. Series: Materials Science and Engineering 180 (2017) 012260 doi:10.1088/1757-899X/180/1/012260

[5] Ganong William F., Physiology of Medicine (Review of Medical Physiology) Edisi 10 (Jakarta, EGC: 2001), h. 247.

[6] Ibnu khalis 2011 Bikemania Jakarta: Flashbooks

[7] Lauralee Sherwood, Human Physiology $2^{\text {nd }}$ Edition (Jakarta, EGC: 2001), h.34.

[8] M. Anwari Irawan, metabolisme body energy \& exercise. (Polton Sport Science \& Performance Lab, 2007), volume 01 no. 07, h. 2.

[9] Rohankar, et.al 2016, Effect of Swimming, Cycling, Walking and Yoga Exercise on Blood Glucose in Diabetes Mellitus, International Journal of Science and Research (IJSR) ISSN (Online): 2319-7064 Index Copernicus Value (2013): 6.14 | Impact Factor (2014): 5.611WHO Fact Sheet 2017, WHO 2017

[10] Wiarto, Giri, Physiology and Sport (Surakarta: Graha Ilmu, 2012), h. 29. 